\title{
EFFECT OF DEFORMATION PROCESSING ON THE PROPERTIES AND STRUCTURE OF TITANIUM OBTAINED BY PLASTIC DEFORMATION OF HYDROGEN-ALLOYED TITANIUM SPONGE
}

\author{
A. V. Nesterenko ${ }^{1 *}$, V. I. Novozhonov ${ }^{2}$, A. G. Zalazinsky ${ }^{1}$ \\ ${ }^{I}$ Institute of Engineering Science, Ural Branch of the Russian Academy of Sciences, 34 Komsomolskaya st., \\ Ekaterinburg, Russian Federation \\ ${ }^{2}$ M.N. Mikheev Institute of Metal Physics, Ural Branch of Russian Academy of Sciences, 18 S. Kovalevskoi st., \\ Ekaterinburg, Russian Federation \\ *Corresponding author. E-mail: nav@imach.uran.ru ; address for correspondence: ul. Komsomolskaya, 34, \\ Ekaterinburg, Russian Federation. Tel.: +7 (343) 375-35-96; fax: +7 (343) 374-53-30.
}

The effect of hydrogen alloying of titanium sponge on the properties of compacted preforms is experimentally investigated at $170{ }^{\circ} \mathrm{C}, 325^{\circ} \mathrm{C}$ under a pressure $1000 \mathrm{of} \mathrm{MPa}$. The influence of the density of the preforms and the presence of hydrogen in them on the force of direct extrusion at a temperature of $600{ }^{\circ} \mathrm{C}$, the density and mechanical properties of extruded bars has been revealed.

The results show the expediency of using the effect of hydrogen plasticization in manufacturing quasi-monolithic preforms from noncompact raw materials in the form of titanium sponge by plastic forming.

Keywords: titanium sponge, compaction, thermohydrogen alloying of titanium.

DOI: $10.17804 / 2410-9908.2015 .3 .098-108$

\section{References}

1. Hartman A.D., Gerdemann S.J., Hansen J.S. Producing Lower-Cost Titanium for Automotive Applications. JOM, 1998, vol. 50, no. 9, pp. 16-19.

2. Obodovsky E.S., Laptev A.M. Hot extrusion of titanium sponge. Poroshkovaya metallurgiya, 1987, no. 4, p. 19.(In Russian).

3. Zalazinsky A.G., Novozhonov V.I., Kolmykov V. L. et al. Effect of technological factors on the properties of dense briquettes and products made of titanium sponge. Metally, 1997, no. 6, p. 28. (In Russian).

4. Sokolov M.V., Stepanenko V.I., Zalazinsky A.G., Lisin A. L. Modeling of briquette compacting and extrusion of rods made of titanium sponge. Izvestiya vuzov. Tsvetnaya metallurgiya, 2000, no. 4, p. 64. (In Russian).

5. Dring K. Method for production of titanium welding wire. WO/2011/049465, 2011.

6. Dring K., Gulbrandsen-Dahl S., Jensrud O., Kolbu A. Method for production of alloyed titanium welding wire. WO/2012/127426, 2012.

7. $\quad$ Sun Z.M., Wang Q., Hashimoto H., Tada S., Abe T. Synthesis and consolidation of TiAl by MA-PDS process from sponge-Ti and chip-Al. Intermetallics, 2003, vol. 11, pp. 63-69.

8. Zadra M. Ficile mechanical alloying of titanium sponge. Materials Science\&Engineering, 2014, vol. A590, pp. 281-288.

9. Zwicker U., Schleicher H. Titanium Alloys Deformabiliti Improvement Technigue during Hot Pressure Shaping. Patent 2892742 (USA), 1959.

10. Aksenov Yu.A, Bashkin I.O., Kolmogorov V.L. et al. Effect of hydrogen on the plasticity and strain resistance of commercial titanium BT10 at temperatures below $750{ }^{\circ} \mathrm{C}$. Fizika metallov $i$ metallovedenie, 1989, vol. 67, iss. 5, pp. 993-999. (In Russian).

11. Murzinova M.A., Salishchev G.A., Afonichev D.D. et al. Effect of hydrogen concentration on the transformation of the microstructure of the VT10 alloy under hot deformation. Metally, 2000, no. 6, p. 73. (In Russian) 


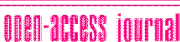

12. Gidridy titana. $V$ kn.: Gidridy metallov [Titanium hydrides. In : Metal Hydrides, ed.: Mueller W. M., Blackledge J. P., Libowits G G.]. New York, Academic Press, 1968, Russian translation: Moscow, Atomizdat, 1973, p. 278. (In Russian)

13. Smirnov S.V., Nesterenko A.V., Bykov V.N., Mikhailov V.G. Deformation properties of sintered tungsten-based heavy alloys. Russian metallurgy (Metally), 2007, vol. 2007, no. 6, pp. 506-513.

14. Smirnov S.V., Nesterenko A.V., Shveikin V.P. Deformability of molybdenum during the production of thin-wall pipes. Russian metallurgy (Metally). 2008, vol. 2008, no. 5, pp. 425-433. 
Подана в печать: 15.05 .2015

УДК 621.777:669.2

DOI: $10.17804 / 2410-9908.2015 .3 .098-108$

\title{
ВЛИЯНИЕ ДЕФОРМАЦИОННОЙ ОБРАБОТКИ НА СВОЙСТВА И СТРУКТУРУ ТИТАНА, ПОЛУЧЕННОГО ПЛАСТИЧЕСКОЙ ДЕФОРМАЦИЕЙ ТИТАНОВОЙ ГУБКИ ЛЕГИРОВАННОЙ ВОДОРОДОМ
}

\author{
А. В. Нестеренко ${ }^{1 *}$, В. И. Новожонов ${ }^{2}$, А. Г. Залазинский ${ }^{1}$ \\ ${ }^{l}$ Федеральное государственное бюджетное учреждение науки Институт машиноведения Уральского отделе- \\ ния Российской академии наук, ул. Комсомольская, 34, Екатеринбург, Российская Федерачия \\ ${ }^{2}$ Федеральное государственное бюджетное учреждение науки Институт физики металлов имени М.Н. Ми- \\ хеева Уральского отделения Российской академии, ул. С. Ковалевской, 18, Екатеринбург, Российская Федера- \\ иุия \\ *Ответственный автор. Электронная почта: nav@imach.uran.ru; адрес для переписки: ул. Комсомольская, 34, \\ Екатеринбург, Российская Федерация. Телефон: +7 (343) 375-35-96; факс: +7 (343) 374-53-30.
}

Экспериментально исследовано влияние водородного легирования на свойства брикетов, полученных из титановой губки марки ТГ-100 при температурах $170{ }^{\circ} \mathrm{C}, 325^{\circ} \mathrm{C}$. Определено влияние плотности титановых брикетов и наличия в них водорода на усилие прямого прессования брикетов при температуре $600{ }^{\circ} \mathrm{C}$, плотность и механические свойства прессованных прутков.

Полученные результаты показывают целесообразность использования эффекта водородного пластифицирования при изготовлении квазимонолитных заготовок из некомпактного сырья в виде титановой губки методами обработки давлением.

Ключевые слова: титановая губка, компактирование, прессование брикетов, термоводородное легирование.

\section{1. Введение}

Для изготовления изделий из титана, которые широко применяются в авиа- и ракетостроении, судостроении, энергомашиностроении и в других областях промышленного комплекса, в настоящее время применяется многоступенчатая, энерго- и трудозатратная технология. В соответствии с существующей технологией из губчатого титана прессованием изготавливают электрод, который подвергают неоднократному вакуумному переплаву и затем из полученного крупногабаритного слитка путем дальнейшей деформационной с промежуточными термическими обработками изготавливают полуфабрикаты, из которых механической обработкой получают изделия, при этом большое количество металла уходит в стружку. Сфера применения титана в промышленности могла бы быть существенно расширена при снижении стоимости титановых изделий. По оценке [1], в стоимости изделий из титана доля стоимости исходного сырья - титановой губки - составляет лишь около $25 \%$.

Перспективным вариантом снижения себестоимости титановых изделий является обработка давлением губки, которая привлекла к себе внимание достаточно давно [2, 3]. В этих работах была показана возможность изготовления титановых изделий (например запорной арматуры для трубопроводов в химической промышленности) с физико-механическими свойствами, близкими к регламентируемым для технического титана, путем обработки давлением титановой губки, минуя операции выплавки слитков. В работе [4] описаны эксперименты по получению прессованных из титановой губки прутков, имеющих свойства, близкие к регламентируемым для прутков, полученных по традиционной технологии. В работе [5] запатентована технология получения сварочной проволоки путем обработки давлением титановой губки, без применения расплавления титана. Имеются также работы, в которых ти- 
тановая губка используется как исходный материал при производстве титановых сплавов методами механического легирования [6-8].

Анализ приведенных выше работ показывает, что после изготовления высокоплотных брикетов целесообразно производить их прямое прессование через коническую матрицу с получением прутков или полосы. При прессовании благоприятная схема напряжённого состояния сочетается со значительными деформациями сдвига, что позволяет получать материал с плотностью, близкой к теоретической. Из работ [2-5] следует, что необходимая плотность брикетов и высокие механические свойства прессованных изделий достигались за счет применения значительных степеней обжатий и высоких температур деформирования. Эти факторы негативно влияли на энергоёмкость процесса, приводили к интенсивному износу деформирующего инструмента и газонасыщению титана.

Известен способ [9] водородного пластифицирования титана, взятого в компактном состоянии, который позволяет снизить сопротивление деформации и повысить пластичность титана и его сплавов в температурном диапазоне $200 \ldots 800^{\circ} \mathrm{C}$. После пластической обработки, проведенной при повышенной температуре, водород из титана удаляется отжигом в вакууме - для исключения “водородной хрупкости” изделий в процессе эксплуатации.

По результатам обзора литературы авторами предлагаемой статьи сделан вывод, что целесообразность применения водородного легирования при пластическом деформировании титановой губки для получения квазимонолитного титана не была исследована. С нашей точки зрения есть основания предполагать, что водородное легирование титановой губки перед компактированием позволит получить более плотный брикет без увеличения нагрузок на прессовый инструмент, а также снизит усилие последующего прессования брикета и улучшит механические свойства прутка.

Цель представленной работы - определение влияния легирования водородом титановой губки на усилие компактирование и плотность спрессованных брикетов при различных температурах, а также на усилие экструзии, плотность и механические свойства прессованных титановых прутков.

\section{2. Материал и эксперименты}

В качестве материала для экспериментов брали частицы отсева титановой губки марки ТГ-ОП-1, содержащей согласно ТУ 1715-484-05785388-2005 примеси, масс. \%: 0,24 Fe, $0.064 \mathrm{Mg}, 0.025 \mathrm{Ni}, 0.041 \mathrm{Cr}$, а также газовые примеси в количестве $0.089 \mathrm{Cl}, 0.007 \mathrm{~N}$, $0.041 \mathrm{O}, 0.007$ С. Гранулометрический состав соответствовал частицам, габариты которых имели размеры от 2 до 5 мм. Некоторое количество исследуемого материала легировали водородом до концентрации 0,5 масс. \% водорода. Гидрирование проводилось в вакуумной установке типа Сивертса методом термодиффузии, в качестве источника чистого водорода использовался дигидрид титана. Содержание водорода в титане определялось по изменению давления в калиброванном объеме реактора и контролировалось весовым методом. Состав гидрированного титана соответствовал формуле $\mathrm{TiH}_{0.244}(\approx 0,5$ масс. \% водорода). Проведенный при комнатной температуре на рентгеновском дифрактометре SHIMADZU XRD-7000 рентгеноструктурный анализ показал, что при введении $0,5 \%$ массовых водорода в титане появляются гидридные выделения ( $\gamma$-фаза). Губка без водорода при комнатной температуре представляет собой $\alpha$-фазу титана.

\section{1 Компактирование титановой губки}

Брикеты получали компактированием обычной и гидрированной губки при давлении 1000 МПа и температурах $170{ }^{\circ} \mathrm{C}$ и $325^{\circ} \mathrm{C}$ в замкнутом цилиндрическом контейнере на гидравлическом прессе. В этом процессе реализуется схема деформирования с преобладанием сжимающих напряжений (сдвиговые деформации в объёме частиц губки практически отсутствуют). Концентрация водорода и температуры нагрева при компактировании выбраны с

Nesterenko A. V. et al. / Effect of deformation processing on the properties and structure of titanium obtained 
учетом данных работы [10]. В соответствии с фазовой диаграммой, приведенной в этой работе, титан не содержащий водород находится в $\alpha$-области при $170{ }^{\circ} \mathrm{C}$ и $325^{\circ} \mathrm{C}$, в то время как гидрированный титан при $170{ }^{\circ} \mathrm{C}$ представляет собой смесь эвтектоидного типа ( $\alpha$-фазы и $\gamma$ гидрида), а при $325^{\circ} \mathrm{C} \gamma$-гидрид растворяется с выделением $\beta$-фазы. Согласно [11], при этом водород вытесняет атомы примесей с дислокаций, что облегчает поперечное скольжение и способствует снижению сопротивления деформации и деформационного упрочнения. Таким образом, выполненное экспериментальное исследование процесса компактирования брикетов при концентрации водорода в титане 0 и 0,5 масс. \% и температуре $170{ }^{\circ} \mathrm{C}$ и $325{ }^{\circ} \mathrm{C}$ позволило оценить влияние фазового состава титана на свойства полученных образцов.

Фактическую плотность брикета определяли по результатам измерения геометриче-

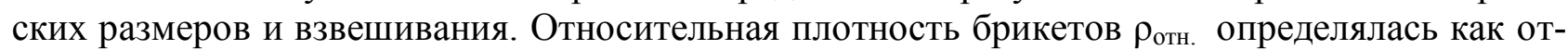

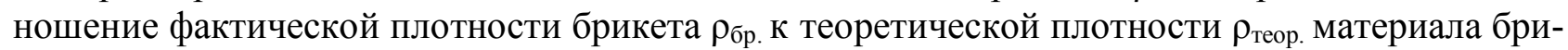
кета. Плотность компактного титана, легированного 0,5 \% массовых водорода, брали по дан-

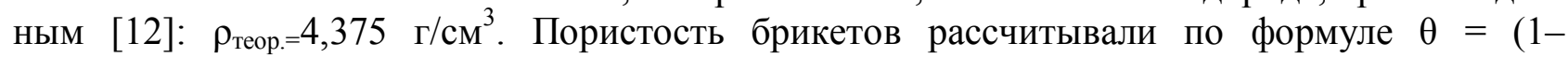

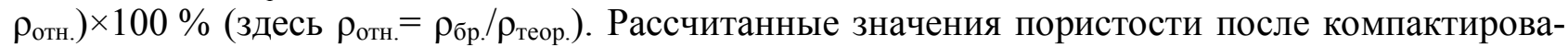
ния при температурах $170{ }^{\circ} \mathrm{C}$ и $325^{\circ} \mathrm{C}$ представлены в табл. 1.

Таблица 1 - Пористость ( $\theta$, \%) брикетов, спрессованных под давлением 1000 МПа

\begin{tabular}{|c|c|c|c|c|c|}
\hline \multirow{2}{*}{$\begin{array}{c}\text { Концентрация } \\
\text { водорода } \mathrm{C}_{\mathrm{H}} \\
\text { масс. } \%\end{array}$} & \multicolumn{5}{|c|}{ Температура компактирования $\Theta,{ }^{\circ} \mathrm{C}$} \\
\cline { 2 - 6 } & 3,0 & 3,6 & 3,5 & 2,8 & $3,1^{*}$ \\
\hline 0 & 7,1 & 7,2 & 2,2 & 2,0 & $0,7^{*}$ \\
\hline 0,5 & \multicolumn{2}{|c|}{170} & \multicolumn{2}{|c|}{325} & 400 \\
\hline
\end{tabular}

* - значения пористости брикетов, рассчитанные по уравнению (2).

На основе данных табл.1 определили влияние на пористость брикетов $(\theta, \%)$ двух факторов: концентрация водорода $\mathrm{C}_{\mathrm{H}}$, масс. \% (уровни 0 и 0,5$)$ и температуры компактирования $\Theta,{ }^{\circ} \mathrm{C}$ (уровни 170 и 325). Для каждой экспериментальной точки в табл.1 приведены результаты двух опытов. Математическую модель зависимости функции отклика $\theta\left(\mathrm{C}_{\mathrm{H}}, \Theta\right)$ задали следующим образом:

$$
\theta=a_{0}+a_{1} \cdot C_{H}+a_{2} \cdot \Theta+a_{3} C_{H} \cdot \Theta
$$

где $a_{0}, a_{1}, a_{2}, a_{3}$ были определены методом регрессионного анализа.

В итоге получили следующее уравнение регрессии:

$$
\theta=3,480+21,140 \cdot C_{H}-0,001 \cdot \Theta-0,065 \cdot C_{H} \cdot \Theta
$$

Для оценки влияния на плотность получаемого брикета изменения фазового состава титановой губки при нагреве до температуры $400{ }^{\circ} \mathrm{C}$ по уравнению (2) вычислили данные для дополнительных точек, относящихся к температуре $400^{\circ} \mathrm{C}$. При этой температуре система Ті-H, согласно фазовой диаграмме, приведенной в [10], с концентрацией водорода, стремящейся к нулю, целиком представляет собой $\alpha$-фазу титана, а при 0,5 масс. $\% H$ состоит из примерно равных по объёму $\alpha$-фазы и более пластичной $\beta$-фазы. Графическая интерпретация зависимости (2) представлена на рис.1. 
Diph-recess jürnal

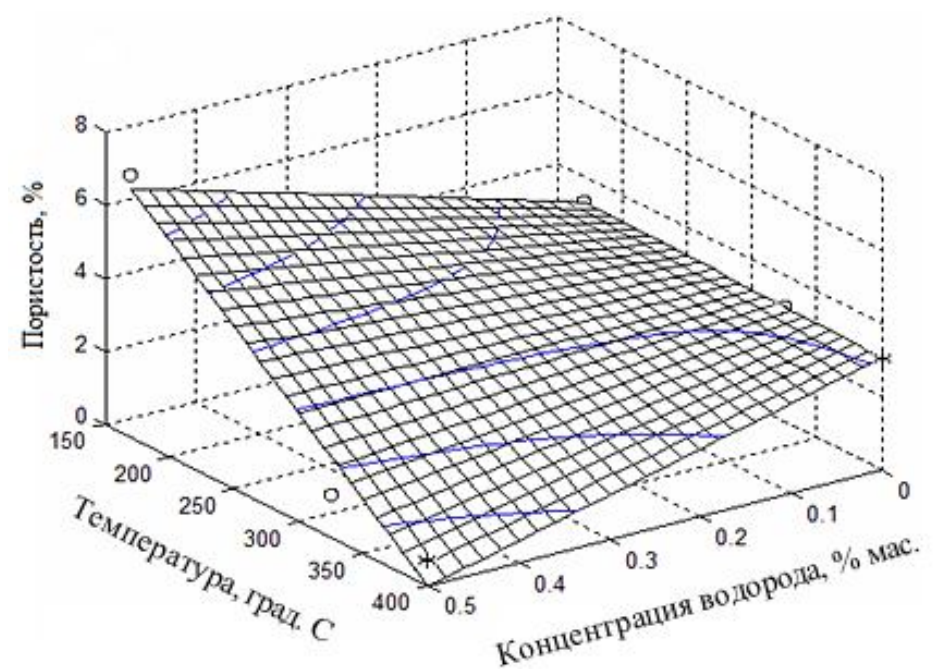

Рис.1. Зависимость пористости $(\theta, \%)$ брикетов от концентрации водорода $\left(\mathrm{C}_{\mathrm{H}}\right.$, масс. \%) и температуры брикетирования $\left(\Theta,{ }^{\circ} \mathrm{C}\right)($ ( - физические эксперименты, *расчет по уравнению регрессии (2))

После компактирования дефекты и загрязнения с поверхности брикетов были удалены минимально необходимой механической обработкой. На рис. 2 представлены снимки характерных фрагментов брикетов, полученных при $325^{\circ} \mathrm{C}$. Снимки сделаны с увеличением в 300 и 1000 раз и показывают участки торцевой поверхности брикетов, имеющих открытую пористость.
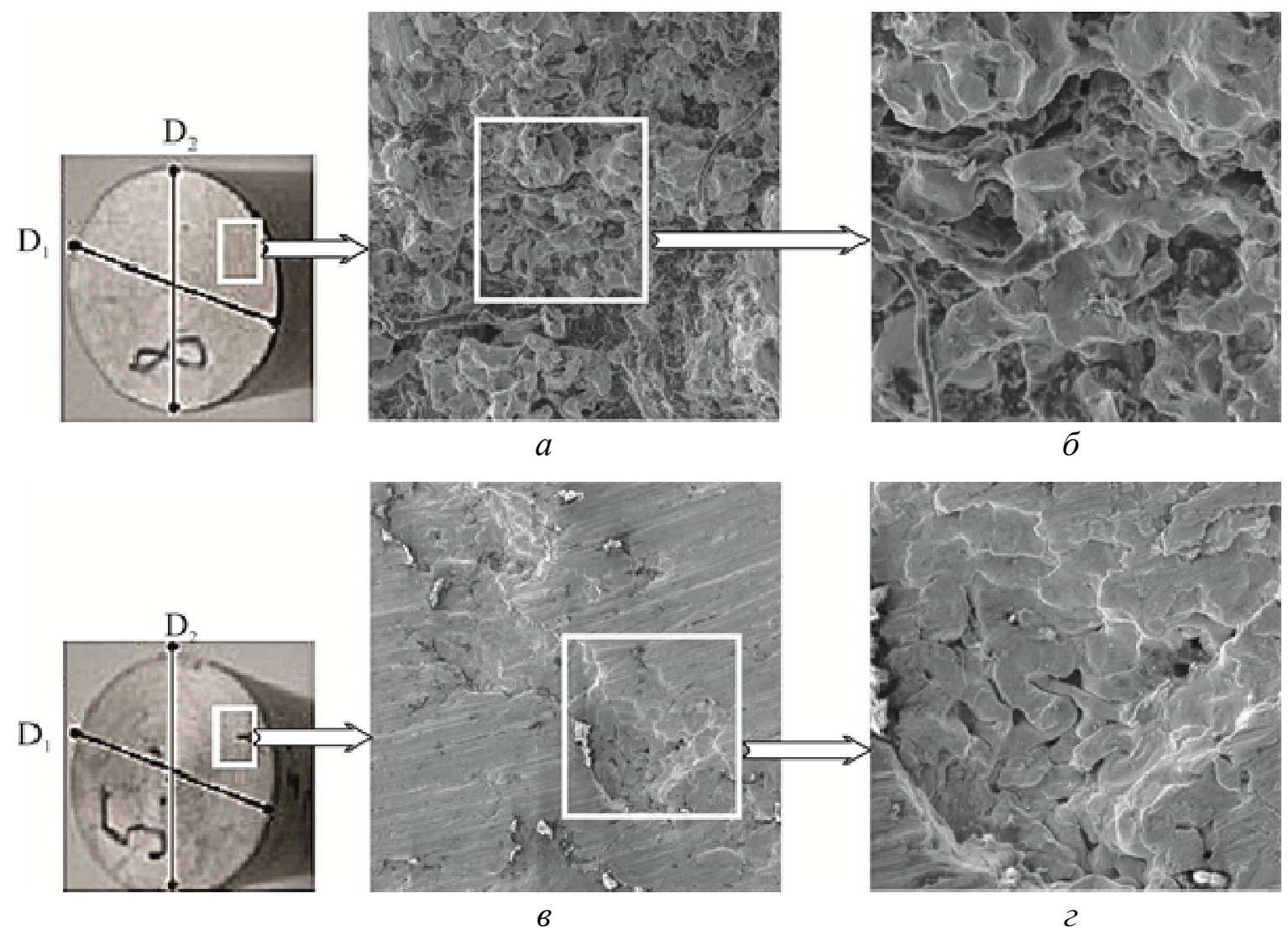

Рис. 2. Характерные фрагменты брикетов, полученных при $325^{\circ} \mathrm{C}$ :

а, б - из губки не содержащей водорода, с пористостью 3,5%,×300 (a), ×1000 (б); в, Г - легированной водородом до 0,5 \% массовых, с пористостью 2,2 \%, ×300 (в), ×1000 (г) 
Для оценки неоднородности механических свойств измерили микротвёрдость. Измерения проводили на торцевой поверхности каждого брикета на микротвердомере Leica VMHT AUTO при комнатной температуре и нагрузке 50 г. Точки поверхности микроиндентировали через 0,4 мм вдоль двух перпендикулярных диаметральных направлений (на рис. 2 обозначены как $\mathrm{D}_{1}$ и $\mathrm{D}_{2}$ ). Первое и последнее измерения проводились в конечных точках диаметрального отрезка. Изменение значений микротвердости в диаметральных направлениях аппроксимировали полиномиальными кривыми (рис. 3).
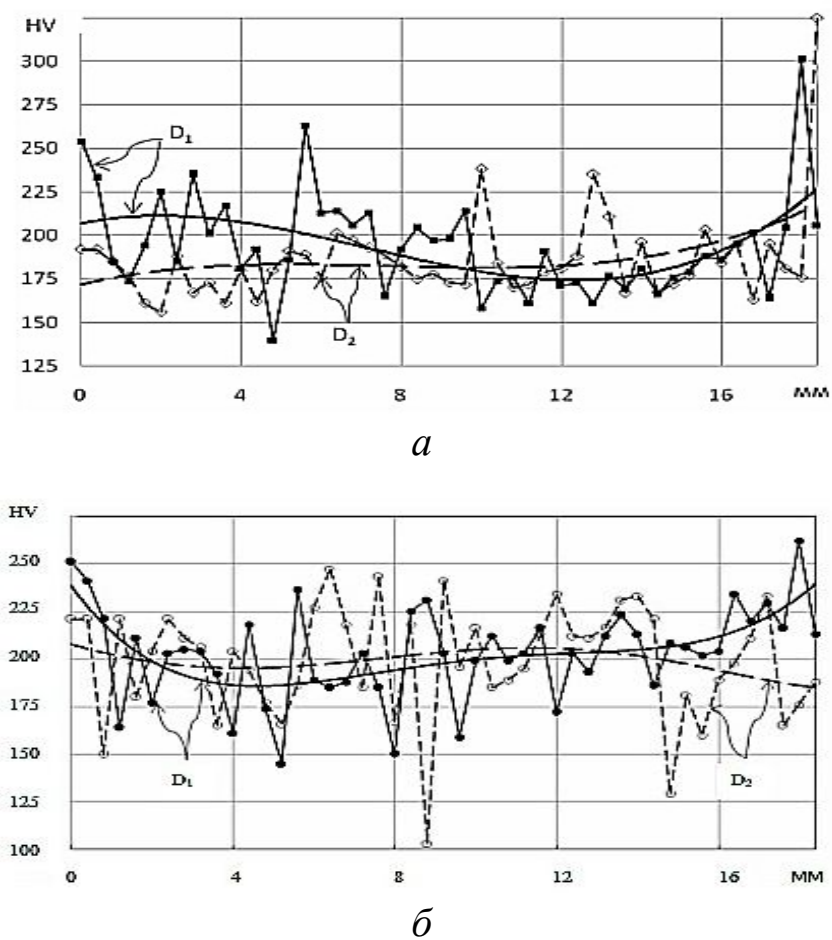

Рис. 3. Распределение микротвердости на торцевой поверхности брикетов: вдоль диаметра $\mathrm{D}_{1}(-\bullet$ измерения, - аппроксимация); вдоль диаметра $\mathrm{D}_{2}$ (---- измерения, -- аппроксимация); $a-$ брикет, не содержащий водород (пористость 3,54 \%);

$\sigma$ - гидрированный брикет (0,5% массовых водорода, пористость 2,24 \%)

\section{2 Прессование брикетов}

Изготовленные из титановой губки брикеты подвергали прямому прессованию через коническую матрицу с коэффициентом вытяжки $\mu \approx 9$. Прессование осуществляли на вертикальном гидравлическом прессе с номинальным усилием 4000 кН. При этом брикеты, помещенные в медную оболочку, перед прессованием нагревали до $600{ }^{\circ} \mathrm{C}$, оснастку для прессования - до $400{ }^{\circ} \mathrm{C}$. В экспериментах оценивали влияние плотности исходного брикета и наличия в нем водорода на усилие прессования, плотность прутков и их механические свойства. Плотность прессованных прутков определяли методом гидростатического взвешивания. Установлено, что на усилие прессования и плотность получаемых прутков существенно влияют начальная плотность брикета и наличие в нем водорода (табл. 2). 
Таблица 2 - Влияние плотности брикетов и наличия в них водорода на усилие прессования и плотность полученных прутков

\begin{tabular}{|c|c|c|c|c|}
\hline $\begin{array}{c}\text { № } \\
\text { брикета, } \\
\text { прутка }\end{array}$ & $\begin{array}{c}\text { Содержание } \\
\text { водорода, } \\
\text { масс. \% }\end{array}$ & $\begin{array}{c}\text { Относительная } \\
\text { плотность брикета, \% }\end{array}$ & $\begin{array}{c}\text { Усилие прессования, } \\
\text { кН }\end{array}$ & $\begin{array}{c}\text { Относительная } \\
\text { плотность прут- } \\
\text { ков, \% }\end{array}$ \\
\hline 1 & 0 & 95 & 1140 & 99,2 \\
\hline 2 & 0 & 97,2 & 1090 & 98,9 \\
\hline 3 & 0,5 & 92 & 1130 & 100 \\
\hline 4 & 0,5 & 98,5 & 950 & 99,8 \\
\hline
\end{tabular}

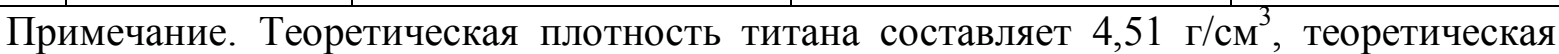

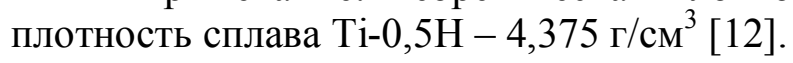

Из табл. 2 видно, что для брикетов № 1 и № 2 различие в исходной плотности $\approx 2,2 \%$ приводит к $\approx 10 \%$-й разнице усилия экструзии. Аналогичная закономерность выявлена и для гидрированных брикетов (№ 3 и 4), плотность которых до прессования различается на $\approx 6,5$ $\%$, а усилие экструзии на $\approx 25 \%$. Рост усилия экструзии при снижении плотности брикетов объясняется увеличением степени окисления по мере уменьшения плотности и более интенсивным охлаждением брикетов с меньшей исходной плотностью вследствие более развитой поверхности. Сравнив результаты эксперимента, полученные для брикетов № 1 и 3, установили, что эффект влияния водородного пластифицирования на усилие экструзии снижается при уменьшении начальной плотности брикета. На основе исследования брикетов № 2 и № 4 пришли к выводу, что увеличение начальной плотности и легирование водородом приводят к снижению усилия экструзии на $\approx 20 \%$. Максимальной относительной плотностью обладают водородсодержащие прутки № 3 и 4 (см. табл. 2).

Для оценки механических свойств прутков, изготовленные из них образцы испытывали на растяжение. Испытания проводились на машине Instron 8801 при скорости активного захвата 1 мм/мин. Поскольку прессованные прутки представляются перспективными заготовками для дальнейшей теплой деформации, температуру испытания выбрали $600{ }^{\circ} \mathrm{C}$. Известно, что при растяжении реализуется схема напряженного состояния с преобладанием растягивающих напряжений. В соответствии с $[13,14]$ пластические свойства металлов в условиях преобладания растягивающих напряжений существенно ниже, чем в условиях сжимающих напряжений. Особенно актуальна количественная оценка выявленной зависимости для материалов, имеющих внутренние концентраторы напряжений. Таким образом, по результатам испытаний на растяжение, можно произвести оценку пластичности, соответствующей неблагоприятным условиям деформирования прутков изготовленных из титановой губки. Результаты эксперимента представлены в табл. 3. Видно, что при $600{ }^{\circ} \mathrm{C}$ уровень прочностных характеристик $\sigma_{0,2}$ и $\sigma_{\text {в }}$ всех прутков находятся на низком уровне. Пластические характеристики оценивали по относительному удлинению $\delta$, относительному сужению $\psi$ и предельной степени деформации сдвига $\Lambda_{\mathrm{p}}$. Перечисленные характеристики значительно выше для образцов, содержащих $0,5 \%$ водорода. Учитывая, что дальнейшую теплую деформацию исследуемых материалов предполагается осуществлять в условиях преобладания напряжений сжатия, пластические свойства деформируемого титана возрастут еще в большей степени.

На рис. 4 и 5 представлены фрактограммы образцов при увеличении в 80 и 1000 раз (на рис. 4 - без водорода и на рис. 5 - с содержанием водорода $0,5 \%$ ), полученные на сканирующем электронном микроскопе Tescan Vega II XMU. На рис.5 (наводороженные образцы) видно более развитое пластическое течение материала в шейке. 
Таблица 3 - Механические свойства прессованных прутков при растяжении (температура испытания $600^{\circ} \mathrm{C}$ )

\begin{tabular}{|c|c|c|c|c|c|}
\hline $\begin{array}{c}\text { № брикета, из которого } \\
\text { получен пруток }\end{array}$ & $\sigma_{0,2}$, МПа & $\sigma_{\mathrm{B}}, \mathrm{MПа}$ & $\delta, \%$ & $\psi, \%$ & $\Lambda_{\mathrm{p}}$ \\
\hline 1 & 25,4 & 30 & 45 & 79,6 & 2,75 \\
\hline 2 & 23,8 & 28,7 & 16 & 44 & 1,01 \\
\hline 3 & 13,5 & 15,8 & 58,6 & 99,2 & 8,33 \\
\hline 4 & 22,4 & 28,1 & 74,7 & 98,6 & 7,36 \\
\hline
\end{tabular}
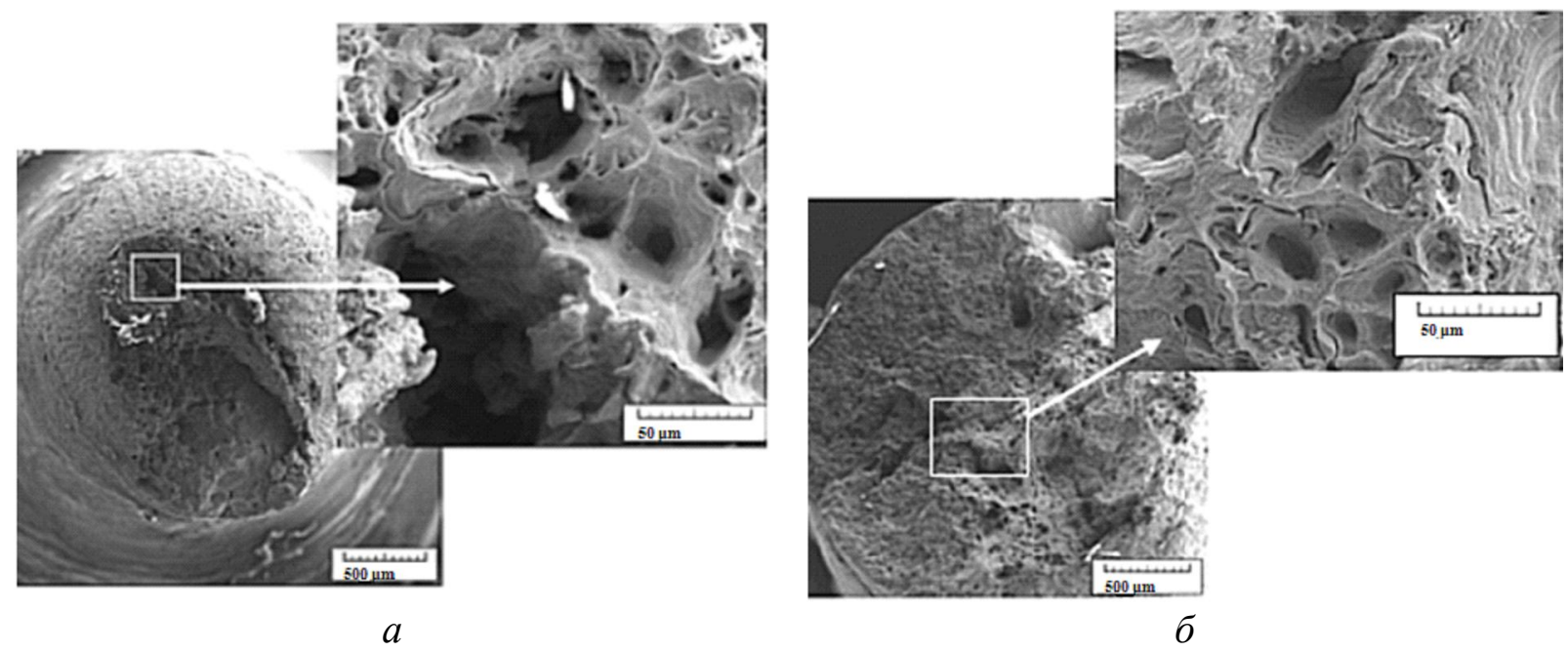

Рис. 4. Вид разрушения негидрированных образцов $(\times 80, \times 1000)$. Материал образца описан в табл. 2: $a$ - пруток № $1 ; \sigma-$ пруток № 2

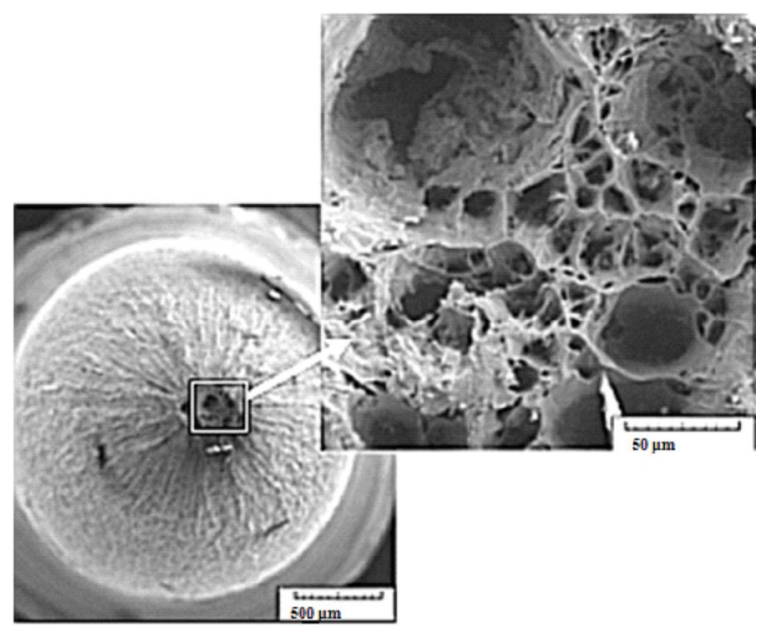

$a$

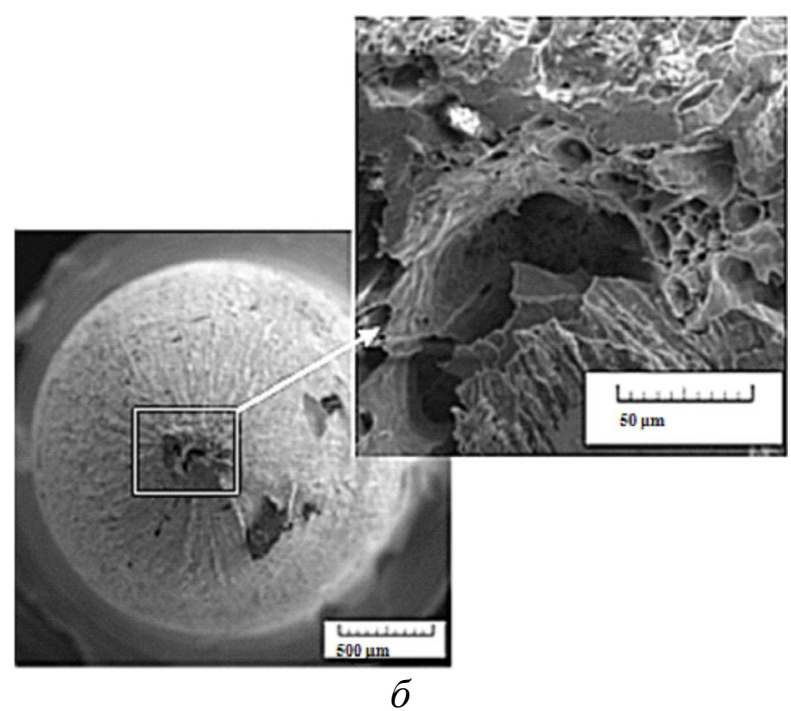

Рис. 5. Вид разрушения гидрированных образцов $(\times 80, \times 1000)$.

Материал образца описан в табл. 2: $a$ - пруток № $3 ; \sigma-$ пруток № 4

Учитывая, что плотность гидрированных образцов 3 и 4 близка к теоретической, выполнили сравнение их деформационных свойств с данными работы [10], в которой исследовались образцы изготовленного по традиционной технологии титана, содержащие 0,5 масс. \% водорода. Изготовленные посредством пластической деформации наводороженной титановой губки прутки № 3 и 4, по сравнению с образцами, исследованными в работе [10], при $600{ }^{\circ} \mathrm{C}$ обладают более низким сопротивлением деформации, при этом их пластичность 
$\Lambda_{\mathrm{p}} \approx 7 \div 8$. Такие свойства обеспечивают высокую деформационную способность даже при достаточно неблагоприятных схемах напряженного состояния, что позволяет подвергать материал большим разовым суммарным деформациям.

Микроструктуру прутка, полученного прессованием брикета, изготовленного из наводороженной титановой губки, изучали с использованием сканирующего электронного микроскопа. При этом рассматривали шлиф продольного сечения образца № 4, разрушенного в испытании на растяжение. Установили, что в структуре металла присутствуют микропоры, вытянутые вдоль направления прессования (рис. 6); размеры пор не превышают 100 мкм.

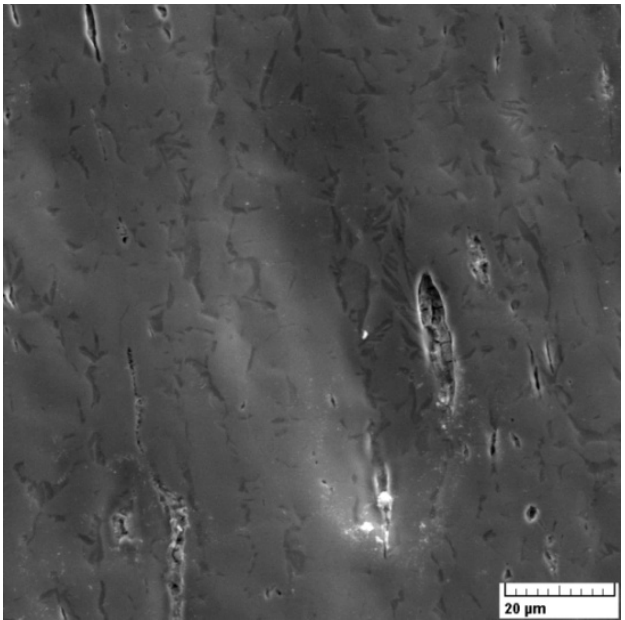

$a$

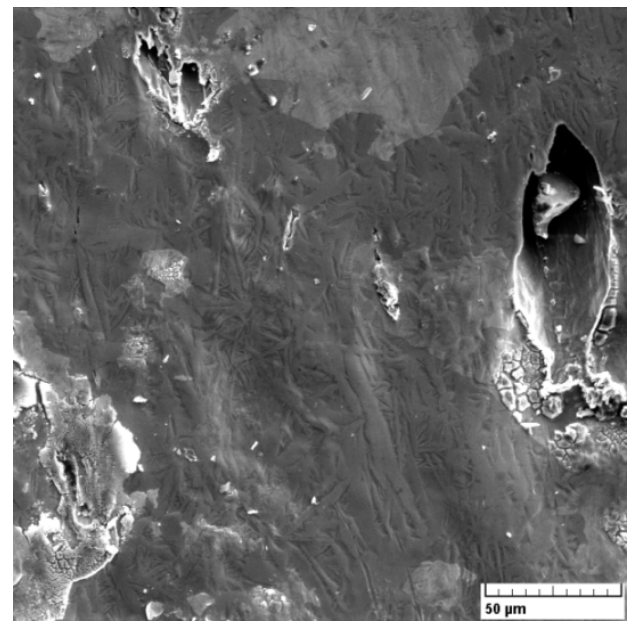

б

Рис.6. Продольное сечение образца № 4, разрушившегося при растяжении: $a-$ участок равномерной деформации $(\times 2000) ; \sigma-$ зона локализованной деформации $(\times 1000)$.

Образец изготовлен прессованием гидрированного брикета с относительной плотностью $98,5 \%$, температура прессования и испытания $600{ }^{\circ} \mathrm{C}$

\section{4. Выводы}

1. В экспериментах количественно определено влияние термоводородной обработки титановой губки на плотность брикетов. Установлено, что введение водорода в губку может оказывать не только положительное, но и отрицательное влияние на процесс уплотнения брикетов, в зависимости от температуры их компактирования. На основе двухфакторной регрессионной модели, заданной уравнением (2) рассчитана относительная плотность брикетов при компактировании титановой губки с нагревом до $400{ }^{\circ} \mathrm{C}$.

2. Измерения микротвёрдости показали, что на неоднородность механических свойств изготовленных брикетов существенно влияют химическая и структурная неоднородность исходной титановой губки и напряжения контактного трения.

3. При прямом прессовании скомпактированных из титановой губки брикетов эффект водородного пластифицирования титана проявляется в существенном снижении (до 25 \%) давления на пуансон и в повышении макроскопической плотности прутков до 99,8 $\div 100 \%$.

4. Экспериментально установлено, что прессованные прутки, изготовленные из титановой губки, изначально содержащей водород, обладают высокими деформационными свойствами при $600{ }^{\circ} \mathrm{C}$ в условиях растягивающих напряжений, что даёт возможность подвергать такой материал большим деформациям без разрушения. Установлено, что заметное повышение прочностных свойств титановых прутков достигается увеличением плотности брикетов.

5. Брикеты, полученные компактированием гидрированной губки, можно рекомендовать для использования в качестве заготовок для изготовления изделий, не регламентируемых высокими эксплуатационными свойствами. 
Исследования проведены по инициативе члена-корреспондента РАН В.Л. Колмогорова в соответствии с планами работ ИМАШ УрО РАН и программы Президиума РАН № 25 (проект 12-П-1-1027).

Испытания на растяжение проведены на оборудовании Центра коллективного пользования ИМАШ УрО РАН. Авторы выражают благодарность д.ф.-М.н. А. В. Скрипову за проведение термоводородной обработки титановой губки, к.т.н. Д.И. Вичужанину за проведение механических испытаний, к.ф.--м.н. С. М. Задворкину за проведение рентгеноструктурных исследований, Е. Б. Трушиной за проведение электронной микроскопии, Н. П. Антеноровой за проведение измерений микротвердости.

\section{Литература}

1. Hartman A. D., Gerdemann S. J., Hansen J. S. Producing Lower-Cost Titanium for Automotive Applications // JOM. - 1998. - Vol. 50, no. 9. - P. 16-19.

2. Ободовский Е. С., Лаптев А. М. Горячая экструзия титановой губки // Порошковая металлургия. - 1987. - № 4. - С. 19.

3. Влияние технологических факторов на свойства плотных брикетов и изделий из титановой губки / А. Г. Залазинский, В. И. Новожонов, В. Л. Колмыков и др. // Металлы. - 1997. - № 6. - С. 28.

4. Моделирование прессования брикетов и выдавливания прутков из титановой губки / М. В. Соколов, В. И. Степаненко, А. Г. Залазинский, А. Л. Лисин // Известия вузов. Цветная металлургия. - 2000. - № 4. - С. 64.

5. Method for production of titanium welding wire : WO/2011/049465 / Dring K. - Publication Date: 28.04.2011.

6. Method for production of alloyed titanium welding wire : WO/2012/127426 / Dring K., Gulbrandsen-Dahl S., Jensrud O., Kolbu A. - Publication Date: 27.09.2012.

7. Synthesis and consolidation of TiAl by MA-PDS process from sponge-Ti and chip-Al / Z. M. Sun, Q. Wang, H. Hashimoto, S. Tada, T. Abe // Intermetallics. - 2003. - Vol. 11. P. 63-69.

8. Zadra M. Ficile mechanical alloying of titanium sponge // Materials Science\&Engineering. 2014. - Vol. A590. - P. 281-288.

9. Titanium Alloys Deformabiliti Improvement Technigue during Hot Pressure Shaping : Patent 2892742 (USA) / Zwicker U., Schleicher H. - 1959.

10. Влияние водорода на пластичность и сопротивление деформации технического титана ВТ10 при температурах до $750{ }^{\circ}$ С. / Ю. А. Аксенов, И. О. Башкин, В. Л. Колмогоров и др. // Физика металлов и металловедение. - 1989. - Т. 67, вып. 5. - С. 993-999.

11. Влияние концентрации водорода на преобразование микроструктуры сплава ВТ1-0 при горячей деформации / М. А. Мурзинова, Г. А. Салищев, Д. Д. Афоничев и др. // Металлы. - 2000. - № 6. - С. 73.

12. Гидриды титана. - В кн. : Гидриды металлов / Под ред. В. Мюллера, Д. Блэкледжа, Дж. Либовица. - М. : Атомиздат, 1973. - С. 278.

13. Deformation properties of sintered tungsten-based heavy alloys / S. V. Smirnov, A. V. Nesterenko, V. N. Bykov, V. G. Mikhailov // Russian metallurgy (Metally). - 2007. - Vol. 2007, no. 6. - P. 506-513.

14. Smirnov S. V., Nesterenko A. V., Shveikin V. P. Deformability of molybdenum during the production of thin-wall pipes // Russian metallurgy (Metally). - 2008. - Vol. 2008, № 5. P. 425-433. 